\title{
Use of Geomatic Approaches to Characterize Arqa River Basin: A Typical Coastal Lebanese River
}

\author{
Abdulrahim Ibrahim 1*, Moustafa Al Hajj ${ }^{2}$, Mhamad El Hage ${ }^{3}$ \\ ${ }^{1}$ Department of Geography (GISRS Lab), Lebanese University, Tripoli, Lebanon \\ ${ }^{2}$ Centre for Language and Communication Studies, Lebanese University, Beirut, Lebanon \\ ${ }^{3}$ Department of Geography (GISRS Lab) and Department of Civil Engineering, Lebanese University, \\ Tripoli, Lebanon \\ Email: ${ }^{*}$ abdelrahimibrahim@hotmail.com, moustafa.alhaji@ul.edu.lb, mhamad.elhage@yahoo.com
}

Received 2 April 2015; accepted 16 June 2015; published 23 June 2015

Copyright (C) 2015 by authors and Scientific Research Publishing Inc.

This work is licensed under the Creative Commons Attribution International License (CC BY).

http://creativecommons.org/licenses/by/4.0/

(c) (i) Open Access

\section{Abstract}

Water resources in Lebanon are one of the major threatened natural resources, since they spread on different geographic locations creating a network of permanent and temporary watercourses that govern the socio-economy and livelihood. However, lately, these watercourses, and certainly the rivers and streams, are witnessing unfavorable impacts that make them with less benefit and use. In addition, most of the Lebanese river basins have not been characterized due to the newly physical challenges of climate change and the human interference. Hence, characterization of the Lebanese river basins must be obtained in order to monitor the changing of physical and anthropogenic parameters. This can help for better conservation and adaptation approaches, notably for climate change. Arqa River, a coastal Lebanese river in North Lebanon is a typical example. In this study, Arqa River basin and the occupied streams among it have been studied using new advanced geomatic techniques. These techniques are based on the treatment of digital geo-spatial data in systematic approaches. ArcGIS is the software which is used to elaborate and manipulate (data interrelation, measures, overlapping, ordering, etc.) the geo-spatial data. Thus, the geometric and morphometric analysis were obtained for the river catchment and the existing tributaries. This will be a primary tool for further applications including water resources management in the river system. This can be utilized in the execution of dams, mountain lakes, man-made channels and in mapping flood-prone areas. In addition, the obtained characterization of this basin will be helpful in mapping erosion processes and estimation of the infiltration capacity, plus monitoring surface water flow. It is a typical approach of analysis that can be applied for the rest of Lebanese river systems in order to attain a better water resources management. This study shows that the use of geomatic techniques is a very helpful tool in the study of basins morphometry, and it can give val-

${ }^{*}$ Corresponding author.

How to cite this paper: Ibrahim, A., Al Hajj, M. and El Hage, M. (2015) Use of Geomatic Approaches to Characterize Arqa River Basin: A Typical Coastal Lebanese River. Open Journal of Modern Hydrology, 5, 45-57.

http://dx.doi.org/10.4236/ojmh.2015.53005 
uable measures which cannot be applicable by conventional tools of analysis. In addition, it serves in reducing time of analysis with least cost, as well as it can cover rugged and remote areas.

\author{
Keywords
}

Geomatic, Remote Sensing, GIS, DEM, Morphometry

\title{
1. Introduction
}

The physical setting of Lebanon, as elongated mountain chains trending in the NNE-SSW direction parallel to the Mediterranean Sea, shapes the distribution of different geomorphologic features, and thus controls the hydrological regime of the running water. For this reason, Lebanon is characterized by a typical geography that makes it distinguished from the surrounding regions.

The Lebanese mountainous nature makes it as a meteorological barrier that captures the cold air masses derived from west, and then condenses these masses on the elevated regions. Therefore, torrential rainfall and snow exist, and consequently, the water derived from rain and snowmelt feeds rivers, springs and groundwater as well. Hence, dense stream networks occur and run water for long time period.

The combination between the topography setting and the existing meteoric water sources results permanent and temporary watercourses along the slopping surfaces. Thus, Lebanon with its relatively small area $(10,452$ $\mathrm{km}^{2}$ ) occupies 15 permanent watercourses (i.e. rivers) and a doubled number of streams (i.e. temporary watercourse). These courses comprise a number of catchment areas "Watersheds" among the existing topographic bodies [1].

Among the 15 rivers, there are 12 coastal rivers and 3 inner ones. In addition, three rivers are shared with the neighbouring regions. The Lebanese rivers, notably the coastal ones, are considered as small-scale river type, since they encompass short length $(<70 \mathrm{~km})$, small catchment areas $\left(<500 \mathrm{~km}^{2}\right)$ and even they have a relatively low discharge rate, which is lower than 300 million $\mathrm{m}^{3} /$ year.

Arqa River is a typical coastal Lebanese river located in the northern part of Lebanon and characterized by ordinary hydrologic characteristics. However, the river among its small-scale watershed comprises unique aspect of landscape. The threshold of Arqa River Basin (ARB) extends from the mountainous ridges to the east and thus extends to the west on a flat coastal plain. Hence, it occupies several issuing springs that feed the river water, such as Nabaa Al-Sheikh Jnayed, Nabaa Al-Shouh, Ain Ad-Deleb and Ain Rahmah.

Lebanon is influenced by the changing of climatic conditions with a special emphasis to the decrease in rainfall rate and oscillating in precipitation patterns accompanied with an increase in the temperature rate. This in turn leads to obvious water shortage that followed by severe conditions in water sector and the imbalanced water demand/supply. Thus, the water budget in Lebanon is still undefined and the proposed strategies for water management have not given any benefit yet. Therefore, most of the Lebanese rivers are dry and the run-off lasts only for few months over the year. This can be applied to Arqa River, which has been substantially affected, and the water deficit becomes a common environmental issue.

The coastal plain of Arqa basin is considered as a major cultivated region in North Lebanon, and hence a variety of field crops are produced from this fertile plain. Thus, water consumption for irrigation can be estimated to more than $70 \%$ of the total water uses. By considering the total population among ARB, which is about 120,000 people, thus the amount of water needed is about 265 million $\mathrm{m}^{3} /$ year.

Yet, there are no creditable studies applied to ensure major hydrological elements of the Lebanese rivers. This will help propose better management approaches for water conservation and to adapt the consumption of water resources to the existing climate change.

In this respect, hydrological and geomorphological characteristics are usually applied as prerequisites in order to understand the majority of water flow regime, and thus to figure out the most useful approaches for better water conservation and use. This study represents identical application of the use of geomatic techniques in order to diagnose the main aspects of water flow regime in ARB. It will help in understanding the hydrological behavior of the running water. Therefore, it can be considered as a first-hand information used in water harvesting (e.g. dams, lakes, etc.), water supply management (e.g. conveying channels, etc.), as well as in estimating the water budget of the surface source. 


\section{Study Area}

The selection of the area of study is based on geomorphologic and hydrological considerations, which are comprised by a surface water basin (i.e. watershed) located in the northern part of Lebanon. The basin where Arqa River runs has an area of about $143 \mathrm{~km}^{2}$ and encompasses 23 major villages and towns where Akkar El-Atika, Tekrit and Rahbeh are the most popular ones. It is situated between the following geographic coordinates (Figure 1):

\section{$35^{\circ} 39^{\prime} 19^{\prime \prime} \mathrm{E}$ and $36^{\circ} 15^{\prime} 48^{\prime \prime} \mathrm{E}$}

\&

\section{$34^{\circ} 27^{\prime} 19^{\prime \prime} \mathrm{N}$ and $34^{\circ} 33^{\prime} 47^{\prime \prime} \mathrm{N}$}

ARB composes the highlands to the east where an altitude with more than $800 \mathrm{~m}$ is dominant and several mountain ridges exist, such as Jabbal El-Sanawbar $(840 \mathrm{~m})$ and Tallet El-Bayda $(1105 \mathrm{~m})$, in addition to the presence of many hills with altitudes exceeding $1750 \mathrm{~m}$ to the east. The river is connected with several temporary streams (i.e. wadis), certainly Wadi Kassair, Naher Maiyet and Wadi Abou Kharra.

The geology of ARB constitutes mainly of two rock lithologies. These are:

1) The carbonate rocks with dominant dolomite and limestone that interfered with some marly layers. The serocks are characterized by intensive fracture systems and karstification, where they are well developed among the dolomite stratum. The infiltration rate in these rocks is estimated between $35 \%$ - 40\% [2]. The carbonate rocks belong to the Middle Cretaceous and Upper Jurassic rock formations.

2) Basalt plateaus and nodules of the Pliocene rock formation. This rock type is extremely hard and characterized by a number of fracture systems and joints. The territory where basalts are exposed is well known by fertile soil with tremendous minerals exist.

3) Variety of interbedded marly, marly limestone and clastic rocks which are unconsolidated and almost friable with high susceptibility to erosion processes; and therefore, colluviums and alluvial deposits are the major component mainly among the plain area.

Normally, groundwater in ARB is available, and it principally encompasses two substratum levels, these are the shallow (<100 m depth) and deep ones (almost >300 m depth), where shallow groundwater is often reserved in the friable and detrital rocks almost among the plain region. Besides, the deeper water is stored in the hard

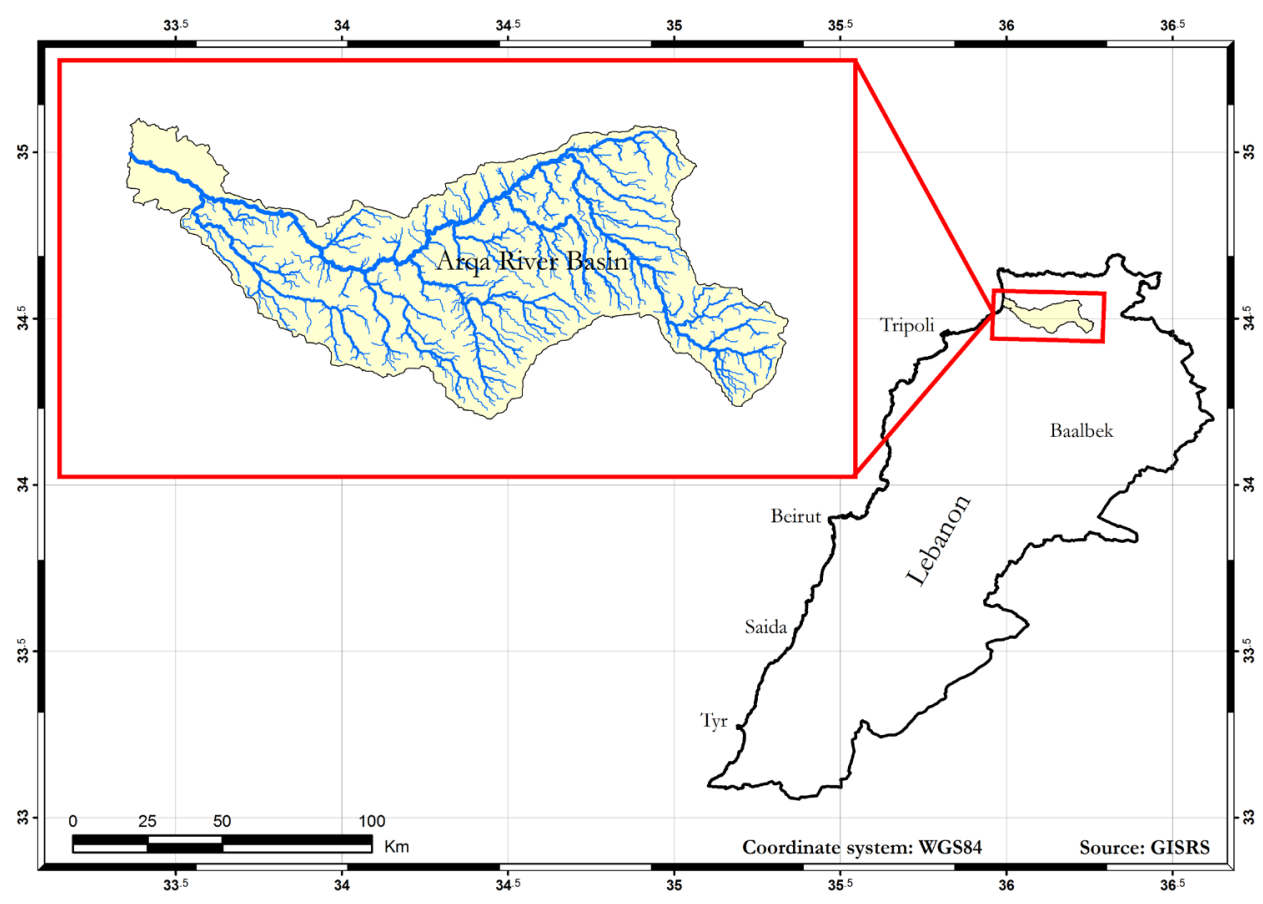

Figure 1. Location map of Arqa River Basin, Lebanon. 
lithologies, and it is normally artesian with considerable discharge.

In addition, there are several indications on the existence of geothermal water. It occurs as water discharges in springs and in boreholes. This has a unique water regime since groundwater is in contact with the basalt rocks at different depths, where temperature gradient is increasing downward. However, such sources are still ignored and their hydrogeological regime is not well understood [3].

\section{Tools and Methods of Analysis}

There are several methods applied for the hydrological and geomorphological analysis where the conventional tools were often used. However, lately new advanced systematic techniques become commonly used. This has been supported by the use of space observations and the geo-information systems. Among these techniques; however, geomatic (or geospatial technology) proved its reliability. It is a systematic tool for data gathering, storing and production of geospatial information.

In this study, the following data and tools were used:

1) Satellite images provided by Google Earth ( $0.5 \mathrm{~m}$ pixel size)

2) Topographic maps (scale 1:50,000)

3) ASTER Global Digital Elevation Model (GDEM) version 2 extracted from ASTER images (1 arcsec resolution)

4) ENVI software

5) ArcGIS (ESRI product) for data manipulation and analysis

Therefore, the following steps were followed:

1) Analysis of topographic maps and supplementary thematic data: This is a preliminary phase to prepare all data and records related to the subject matter. Therefore, hydrological and meteorological records were analysed and compared with data resulted from the geomatic approaches.

In addition, topographic maps scan play a major role in verifying the geomorphologic and hydrologic behaviour of drainages extracted from Digital Elevation Models (DEMs) and thus in recognizing the names of valleys and the related tributaries.

2) Satellite images processing: This is a principal phase used to treat the space observations which can introduce a comprehensive view to terrain surfaces and the existing objectives with a special concern to human settlements and cultivated lands and their influence on drainage behaviour.

Thus, ENVI software was used to process satellite images which are characterized by high resolution. For this purpose, a number of pre-processing applications (i.e. geo-referencing and enhancement) were primarily applied to have enhanced geo-referenced images for a better image analysis.

3) DEM preparation:

ASTER GDEM v2 is a product of the collaboration between the Ministry of Economy, Trade, and Industry (METI) in Japan and NASA in the United States. It covers most of the Earth surface and it is provided online for free to all users. It was produced using ASTER (Advanced Space-borne Thermal Emission and Reflection Radiometer) images by a photogrammetric processing. It has a mesh size of 1 arcsec (30 $\mathrm{m}$ on the equator). GDEM is provided in $1^{\circ} \times 1^{\circ}$ tile in geographic coordinates system. We reprojected it into the Universal Transverse Mercator (UTM) zone 36 north.

The quality of the stream networks depends on the quality and the resolution of the DEM [4]. The geometric accuracy of the stream networks extracted from GDEM is comparable to the mesh of this DEM (30 m) [5]. Moreover, the version 2 of GDEM was improved using SRTM data [6] which made it more suitable for hydrographical modelling [7].

4) Extraction of drainage system from the DEM:

The extraction of drainage system passes through different steps. First, the DEM has to be topographically corrected by filling the sinks. These sinks, if present in the DEM, will be wrongly considered as outlets. Thus, we used the "Optimal Pit Removal" method [8], which has overcome the problem of artificial parallel and elongated streams; with define geometry, produced in flat areas by the traditional filling methods. Then, the flow direction has to be calculated in order to extracts the stream networks and the basin boundary. We used the D8 method available in ArcMap, which is commonly used due to its simplicity and robustness [9]. Flow accumulation and "Strahler" order were then calculated, and the obtained streams were converted from raster to vector mode. Finally, the watershed boundary is extracted using ArcMap algorithm, which utilizes flow direction in order to detect ridgelines in the obtained DEM. 


\section{Results and Data Analysis}

The principal types of the Lebanese watersheds are relatively simple and often occupy rivers of relatively low discharges [10]. This may be attributed to the relative short distances between the headwaters (i.e. highest altitude of water flow) and lowest (discharge) points, which are normally in the range of $30-50 \mathrm{~km}$, as well as the relatively limited area of the replenishment zones.

Accordingly, the optimal characterization of rivers and their catchment areas can be well demonstrated by analysing the geometric characteristics of the basin boundary and then the morphometric characteristics of the drainages situated within the catchment area.

Therefore, the drainage system of Arqa River have been produced using GIS (Figure 2), thus, all numeric values for dimensions (geometric and morphometric) can be calculated and analysed.

\subsection{Geometric Characteristics}

The geometry of surface water basin is considered as a principal hydrologic and geomorphologic aspect upon which several related measures can be accounted. Amongst the major factors controlled by basin geometry is the time lag for water arrival from different tributaries to the primary watercourse (i.e. almost the river course) as well as to the outlet. This is, of course, after considering other factors, such as the slope of the adjacent surfaces and gradient of the major channel, etc.

\subsubsection{Major Basin Dimensions}

Usually the principal geometric measures are primarily calculated as basic datasets describing the entire dimensions of the basin. These dimensions often showing the scale of catchment area where water is collected, and thus it governs the amount of water flow.

Even though in Lebanon, Arqa River basin is considered as a small-scale catchment since it has an area of about $143 \mathrm{~km}^{2}$. The basin is trending mostly in the E-W direction, since the mountain chains are situated to the east, and thus extending seaward.

ARB, which has a perimeter of about $84 \mathrm{~km}$, owns a straight length (i.e. between the maximum apart points) of about $26.5 \mathrm{~km}$ and maximum width of about $9.8 \mathrm{~km}$. It encompasses an average altitude of about $653 \mathrm{~m}$.

\subsubsection{Basin Shape}

The shape of a basin depends on several geomorphological and hydrological factors including mainly geomorphological and climatological factors in addition to the existing rock lithology and structures. Hence, the shape

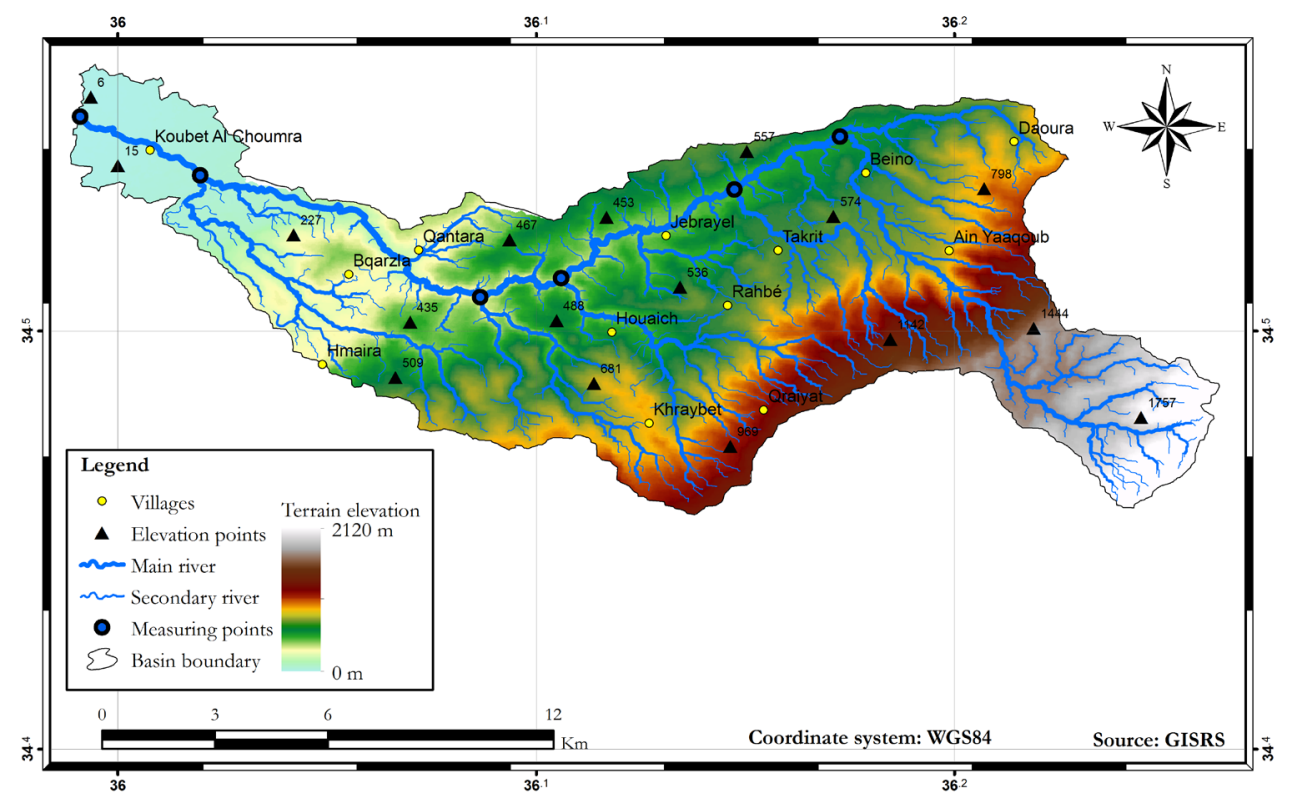

Figure 2. Drainage system of Arqa River Basin on DEM. 
of the basin governs runoff and overland flow regime.

Thus, in a basin with almost a circular shape, water arrives to the main outlet at the same time and this creates a rising in the water level in the primary watercourse. Besides, water arrives sequentially in a basin with almost rectangular shape. Nevertheless, in funnel-like shape basin geometry, the time lag for water to arrive at the outlet is relatively long.

There are several aspects and measures to characterize the basin shape; however, three principal ones will be treated in this research. These are:

1) Elongation ratio $(E)$ : It is the ratio between the diameter of the circle which has the same area of the basin to the distance between the most remote points in the basin [11]. It can be expressed as:

$$
E=\frac{2 \sqrt{A}}{L \sqrt{\pi}}
$$

2) Shape index $(F)$ : It represents the ration between the area of the basin to the distance between the most distant points along the primary watercourse [12]. It can be expressed by the following formula:

$$
F=\frac{A}{L^{2}}
$$

3) Gravelius index $(K)$ : This index expresses the ratio between the perimeter of the basin with respect to a circle with the same area of the basin [13]. Thus, a value of $K$ closer to 1 means that the basin has a circular shape; whilst value higher than 1 means that the basin is mostly elongated. The following formula expresses this shape index:

$$
K=\frac{P}{2 \sqrt{\pi \cdot A}}
$$

Table 1 shows the principal dimensions of ARB, as well as the shape measures obtained in this study. Hence, it is obvious that the catchment area of the basin is of the small-scale type, and it can be considered also as a small basin even with respect to the Lebanese territory. It has a typical elevation and surface slope of the Lebanese coastal mountains, with E-W orientation.

The ratio between the length and width of ARB is about 2.7:1, which indicates that the basin is characterized by almost an elongated shape, notably if the average width (i.e. $5.8 \mathrm{~km}$ ) is accounted. In addition, the ratio between the basin area and perimeter is about 1.7:1, and this shows that the borderline of the basin can be considered as moderately curved (i.e. irregular borderline).

For the shape measures obtained according the common geomorphological formula; however, the elongation ratio $(E)$ with value of 0.51 (Table 1 ), indicates that the boundary of the basin can be cited within almost an ordinary rectangular frame. This shows that the basin is mainly elongated.

According to the shape index $(F)$ with a value of 0.2 (Table 1 ), it reveals that the basin area is small enough with respect to its primary watercourse. While, the value of Gravelius Index $(K=1.99)$ evidences that the basin is also a rectangular rather than circular or fan-like shape.

\subsubsection{Relief}

The impact of relief on flow is well understood since a number of hydrometeorological parameters vary with altitude and watershed morphology, such as the steep sloping relief which accelerates the flow speed [14]. Thus, relief can be determined by means of indices or characteristics curves, such as hypsometric curve which represents the overall view of the slope of the watershed and thus the relief [15].

Hypsometric curve treats a cumulative function of elevations in the watershed, and it can be obtained by

\begin{tabular}{|c|c|c|c|c|c|c|c|c|c|c|}
\hline \multicolumn{8}{|c|}{ Major basin dimensions } & \multicolumn{3}{|c|}{ Basin shape } \\
\hline $\begin{array}{l}\text { Area } \\
\text { (A) }\end{array}$ & $\begin{array}{l}\text { Perimeter } \\
\text { (P) }\end{array}$ & $\begin{array}{l}\text { Length “L” } \\
\text { (maximum) }\end{array}$ & $\begin{array}{l}\text { Width "W" } \\
\text { (maximum) }\end{array}$ & $\begin{array}{l}\text { Average } \\
\text { altitude }\end{array}$ & Slope & $\mathrm{L} / \mathrm{W}$ & $\mathrm{A} / \mathrm{P}$ & $\mathrm{E}$ & $\mathrm{F}$ & $\mathrm{K}$ \\
\hline $143 \mathrm{~km}$ & $84 \mathrm{~km}$ & $26.5 \mathrm{~km}$ & $9.8 \mathrm{~km}$ & $653 \mathrm{~m}$ & $14^{\circ}$ & $2.7: 1$ & $1.7: 1$ & 0.51 & 0.2 & 1.99 \\
\hline
\end{tabular}
measuring the area lying between successive pairs of contours. The percentage of the total that each of these

Table 1. Major dimensions shape measures of ARB. 
areas constitute are then computed, and the percentage of the total area lying above or below each different contour is obtained by summation. Table 2 shows the calculated measure to build the hypsometric curve for ARB.

Figure 3 shows the obtained hypsometric curve of ARB, which has an average altitude of $653 \mathrm{~m}$. It reveals that approximately $10 \%$ of the catchment is characterized by very steep slope among the altitude ranges between 1400 - $950 \mathrm{~m}$ to the east. While about $70 \%$ of the catchment comprises a moderately gentle sloping surface, in with the elevation is less than $900 \mathrm{~m}$. In addition, the curve shows two abrupt signatures at altitudes of approximately $1400 \mathrm{~m}$ and $100 \mathrm{~m}$, which can be attributed to the existence of fault alignment (i.e. rock deformation), folding structure or lithological contacts.

\subsection{Morphometric Characteristics}

As per the morphometry of any drainage basin, it treats the behaviour and dimensions of the stream networks among the basin boundary itself, and the interrelation between these streams, which are the major water flow routes and control the runoff as well as the water level among the existing watercourses.

There are various morphometric characteristics applied on different geomorphological and hydrological studies. In this study, the fundamental ones will be analysed to characterize the drainages within ARB.

\subsubsection{Drainage Density $(D)$}

This property expresses the total length of the existing streams within the basin. It can be diagnosed spatially by dividing the basin into frames with define areas, and thus measuring the length among each frame according to the following formula.

$$
D=\frac{\sum L(\text { total of all streams })}{A(\text { area of the basin })}
$$

Therefore, the general $D$ of ARB equals to $2.8 \mathrm{~km} / \mathrm{km}^{2}$. This is mainly considered as moderate drainage density, which equilibrates between the infiltration capacity and surface flow regime.

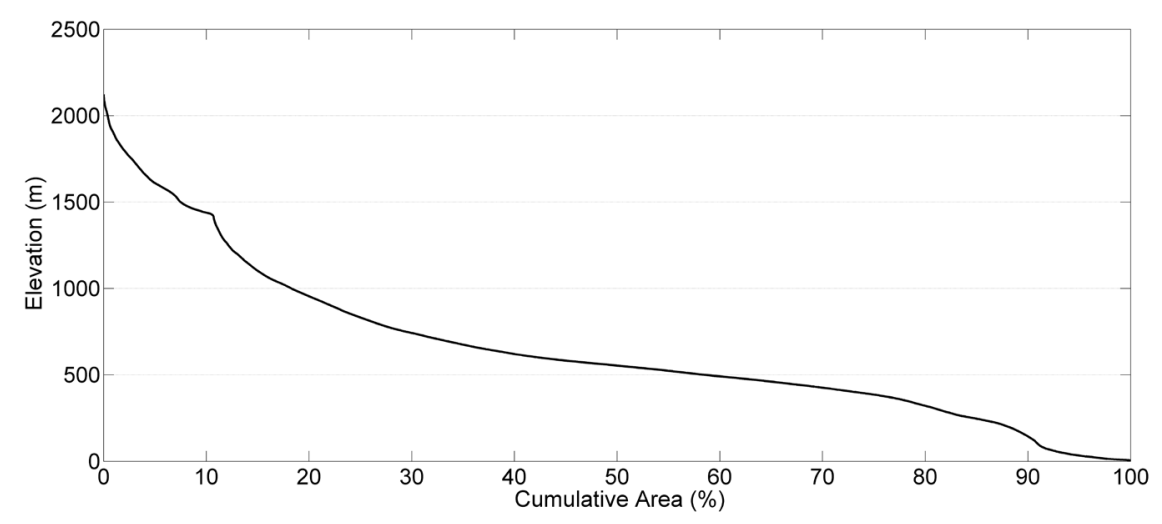

Figure 3. Hypsometric curve of ARB.

Table 2. Elevations and their spatial percentage of ARB.

\begin{tabular}{ccccc}
\hline Elevation interval (m) & Average altitude $(\mathbf{m})$ & Area $\left.\mathbf{( k m}^{\mathbf{2}}\right)$ & Cumulative area $\left.\mathbf{( k m}^{\mathbf{2}}\right)$ & Cumulative area (\%) \\
\hline$<300$ & 132 & 27 & 27 & 18.8 \\
$300-600$ & 474 & 56 & 83 & 57.6 \\
$600-900$ & 722 & 29 & 112 & 77.8 \\
$900-1200$ & 1029 & 13 & 125 & 86.8 \\
$1200-1500$ & 1384 & 8 & 133 & 92.4 \\
$1500-1800$ & 1638 & 8 & 141 & 97.9 \\
$>1800$ & 1912 & 3 & 144 & 100 \\
\hline
\end{tabular}




\subsubsection{Mean Channel Slope $\left(S_{c}\right)$}

It is a simplified criterion that exposes the slope gradient of the primary river course or the major stream channel, since the course receive all loads from different tributaries and usually has larger cross-section area. Therefore, the more the slope gradient of the primary course, the faster the discharge rate at the outlet zone.

It can be calculated by dividing the elevation difference of the endpoints of the primary watercourse on the total length of the same watercourse, as follows:

$$
S_{c}=\frac{\Delta H}{L}
$$

For the watercourse of Arqa River, Sc was found as $26.4 \mathrm{~m} / \mathrm{km}$, which can be considered as a gentle slopping channels and this plays a role in reducing the discharge rate at the outlet (i.e. river mouth).

\subsubsection{Meandering Ratio $\left(M_{r}\right)$}

This morphometric property expresses the straight length of the primary watercourse of the river with respect to its curved length, and can be calculated as follows:

$$
M_{r}=\frac{L(\text { straight })}{L(\text { curved })}
$$

For Arqa River, $M_{r}$ equals 0.71 and this means that the primary river course tends to be moderately straight alignment. Thus, channel load sedimentation will be low to moderate. Moreover, the lower meandering ratio permits increased acceleration of the flow rate among the primary river course.

\subsubsection{Flow Accumulation (Fa)}

This morphometric property is normally used to calculate the sum of streams capacity with respect to a defined point. If the cross-section area of a stream is determined; however, Fa can be a function of water load. Geomatic application can help calculating the flow accumulation of the upstream drainage of a specific site. This can be done by measuring the number of pixels included among the stream.

For Arqa River, six sites were selected in order to calculate the flow accumulation. These represent major confluences as shown in Figure 2 and Table 3.

It is clear that some of sites, with lower sub-catchment area, show discharge capacity higher than the otherones with larger sub-catchment areas. This is dependent on several factors, mainly the infiltration capacity, drainage density and the rainfall and snow cover amount, in addition to the human expansion of settlements.

The total capacity of discharge from Aqra River is about $502 \times 10^{6} \mathrm{~m}^{3}$. However, this is a static discharge volume. Hence, the annual discharge rate will be a function of this capacity in relation to the amount of rainfall.

\subsubsection{Distance to the Outlet (Do)}

This geomorphologic measure has a great importance in dividing the basin into zones, each will be indicative to a specific distance to the outlet, and thus it can be utilized in water supply approaches. This measure, which is often done by using geomatic applications, can be produced in a map form showing different zones with respect to distances from the outlet.

Table 3. Discharge capacity, as indicated from the flow accumulation, at selective confluences in Arqa River.

\begin{tabular}{ccccc}
\hline Site No. & No of pixels & Area of pixels $\left.\mathbf{( m}^{\mathbf{2}}\right)$ & Average stream depth $(\mathbf{m})$ & Water volume $\left(\mathbf{1 0}^{\mathbf{6}} \mathbf{~ m}^{\mathbf{3}}\right)$ \\
\hline 1 & 99061 & 400 & 3.9 & 154.5 \\
2 & 138222 & 400 & 3.6 & 199.0 \\
3 & 223819 & 400 & 3.3 & 295.40 \\
4 & 260836 & 400 & 3.7 & 386.0 \\
5 & 334862 & 400 & 3.6 & 482.2 \\
6 (outlet) $^{*}$ & 348808 & 400 & 3.6 & 502.2 \\
\hline
\end{tabular}

\footnotetext{
*The total drained capacity for the entire basin.
} 
In this study, six outlet-distance zones are identified, as follows: $<9$ km, 9 - 15 km, 15 - 20 km, 20 - 25 km, 25 - $32 \mathrm{~km}$ and $32-40 \mathrm{~km}$ (Figure 4). Thus, it is obvious that the real extent of the identified outlet-distance zones is almost similar. This is an indicative geomorphological criterion that the overall slopping of the basin is gently trending from east to west. In addition, each zone is mainly occupied among a specific configuration of the basin border.

\subsubsection{Stream Order (So)}

It is a major morphometric characteristic that is commonly used to classify the relative location of streams with respect to each other, which is a function of stream connectivity. Thus, a stream of order 1 will form the first reach in the drainage system, and then at the confluence of two streams of order 1 assigns the downstream stream of order 2, and so on [16]. Consequently, a well-known geomorphologic relation can be obtained, the so-called "bifurcation ratio".

From stream order analysis; however, the bifurcation ratio $\left(R_{b}\right)$ is often calculated. It is the ratio between the numbers of streams in one order to the next order. It can be measured as:

$$
R_{b}=\frac{N_{i}}{N_{i+1}}
$$

The number of streams of order $i$ equal to $\left(N_{i}\right)$, and the number of streams in the next order is $N_{i+1}$. Hence, the map of stream orders has been generated by the geomatic applications. Table 4 reveals stream order values, which have been demonstrated in Figure 5.

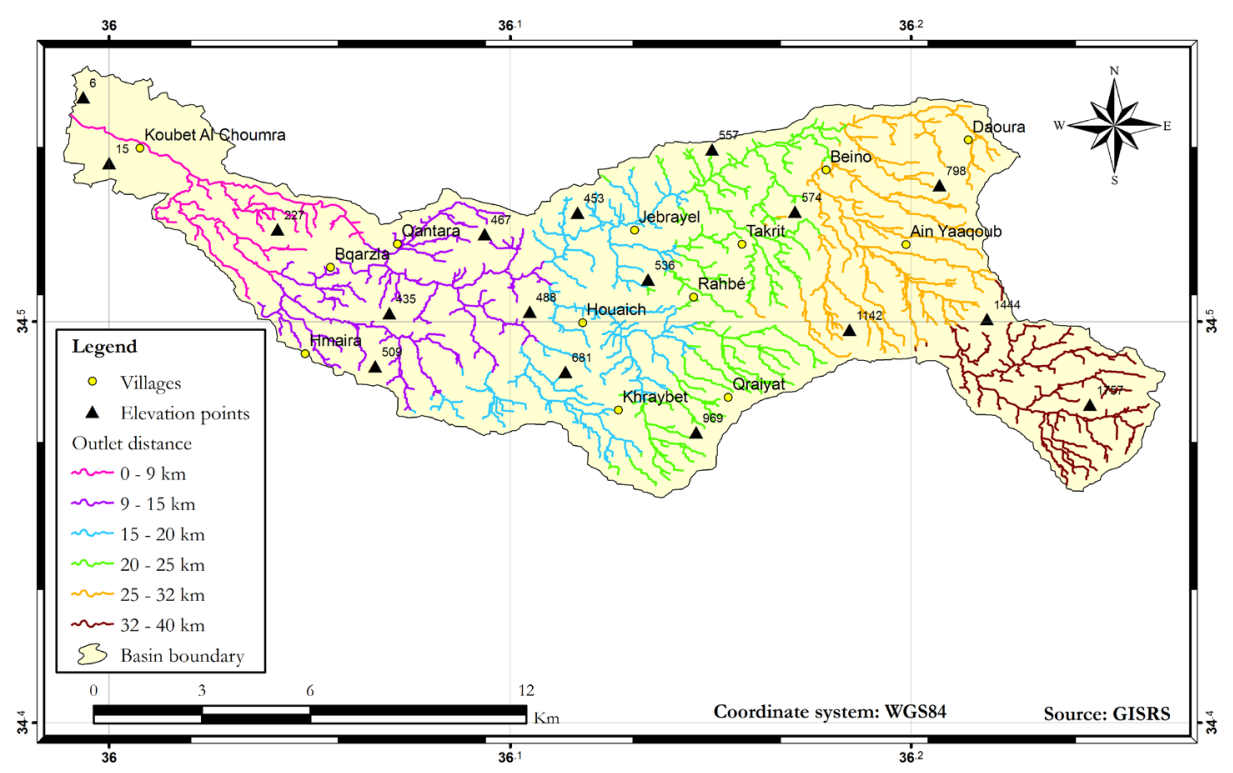

Figure 4. Zones of defined distances to outlet of ARB.

Table 4. Stream orders and their bifurcation ratio of ARB.

\begin{tabular}{cccc}
\hline Stream order & No of streams & Lengths of stream $(\mathbf{k m})$ & Bifurcation ratio $\left(\boldsymbol{R}_{\boldsymbol{b}}\right)$ \\
\hline 1 & 583 & 191 & 4.85 \\
2 & 120 & 111 & 4.8 \\
3 & 25 & 46 & 3.57 \\
4 & 7 & 34 & 7 \\
5 & 1 & 23 & - \\
Total & 736 & 405 & \\
\hline
\end{tabular}




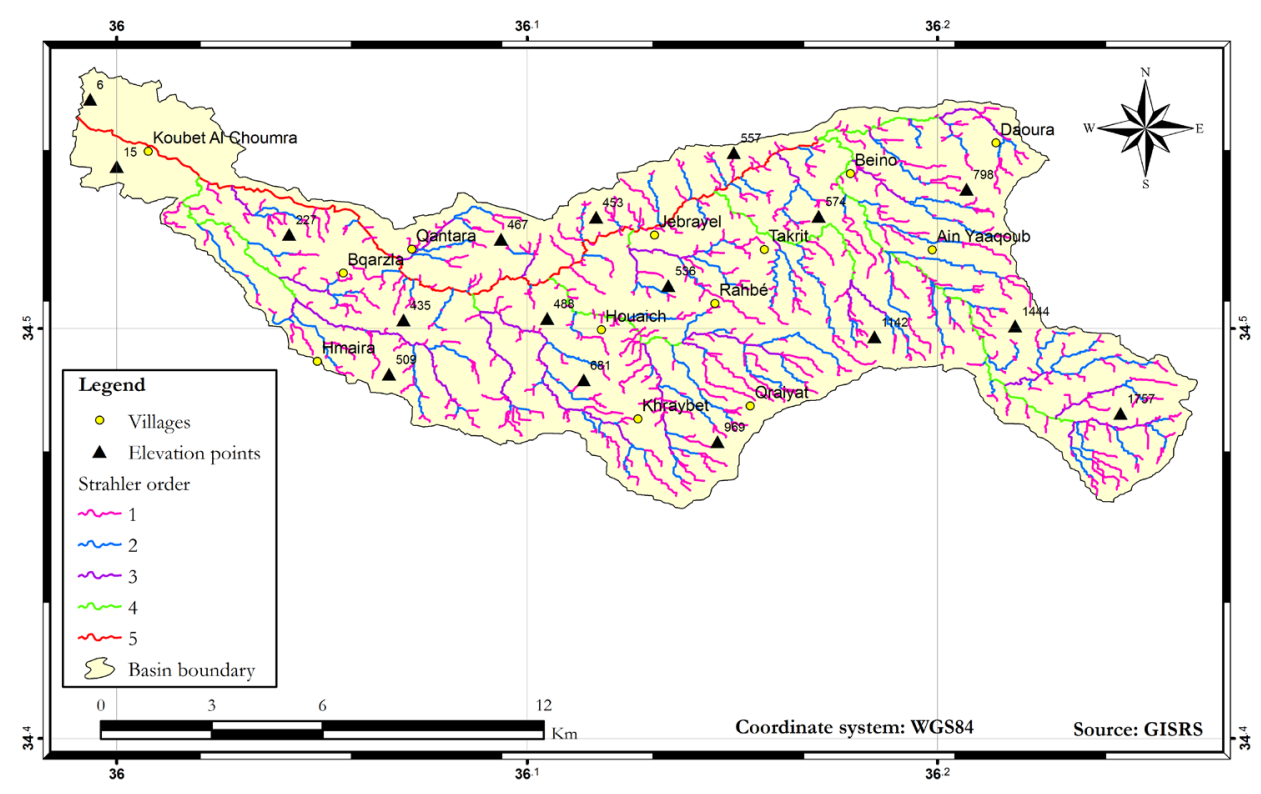

Figure 5. Stream orders of ARB.

Therefore, when $R_{b}$ is high, the flow rate becomes low, and this is indicative to time lag for the infiltration capacity and better groundwater recharge, as well as low probability of flooding exists and vice versa. Thus, for $\mathrm{ARB}$, the average $R_{b}$ is almost high and the difference between the $\mathrm{Rb}$ is almost uniform except for stream order number 4.

\subsubsection{Stream Slopes (Ss)}

This is also another geomorphologic measure which investigates streams (or reaches) separately, and thus it can calculate the slope of these watercourses of diverse dimensions by using the geomatic applications through the utilisation of DEMs.

In this study, a map showing slopes for the different streams, as follows: $<3.5^{\circ}, 3.5^{\circ}-7^{\circ}, 7^{\circ}-11^{\circ}, 11^{\circ}-15^{\circ}$, $15^{\circ}-23^{\circ}, 23^{\circ}-42^{\circ}$, is plotted (Figure 6). Hence, these slopes are known to be as a function of terrain surface slope and lithological characteristics.

Nevertheless, in this study these slopes were compared with the stream orders in order to investigate if any relationship may exist. Therefore, Table 5 shows the slopes of streams and their order. Hence, it was clear that the higher the stream order, the less the slope and vice versa. In addition, slopes of $7^{\circ}-11^{\circ}$ are the most frequent one, and the slopes that range between $3.5^{\circ}-11^{\circ}$ encompasses about $51 \%$ from the total streams in ARB.

\subsubsection{Stream Joining (Sj)}

When two streams are connected, whether as confluences or diversions, they create a hydrologic criterion which is a function of flow rate and uniformity. In other words, the more the number of upstream drainages in connection with a downstream drainage, the higher the flow rate and vice versa. This criterion; however, is indicative to several terrain properties, mainly the lithology and geologic structures of the exposed rocks, as well as the slope.

In this study, the contact points between streams (i.e. confluences and diversions) were plotted on a map using geomatic applications. Therefore, the geographic distribution of the connecting points was extracted showing different zones with stream joining density (Figure 7). Hence zones with high joining points indicate loaded water flow and usually considered as zones under flood risk.

Hence, the extracted map shows five stream joining densities as follow: $<2$ nodes $/ \mathrm{km}^{2}, 2$ - 5 nodes $/ \mathrm{km}^{2}, 5$ - 7 nodes $/ \mathrm{km}^{2}, 7-10$ nodes $/ \mathrm{km}^{2}$ and $>10$ nodes $/ \mathrm{km}^{2}$. Therefore, the dense joining localities can be well observed in the map, such as in the regions near Jebrayel, Houaich and Ain Yaaqoub (Figure 7).

\section{Conclusion and Recommendations}

It is quite obvious that ARB is characterized by elongated shape according to several geometric measures ap- 


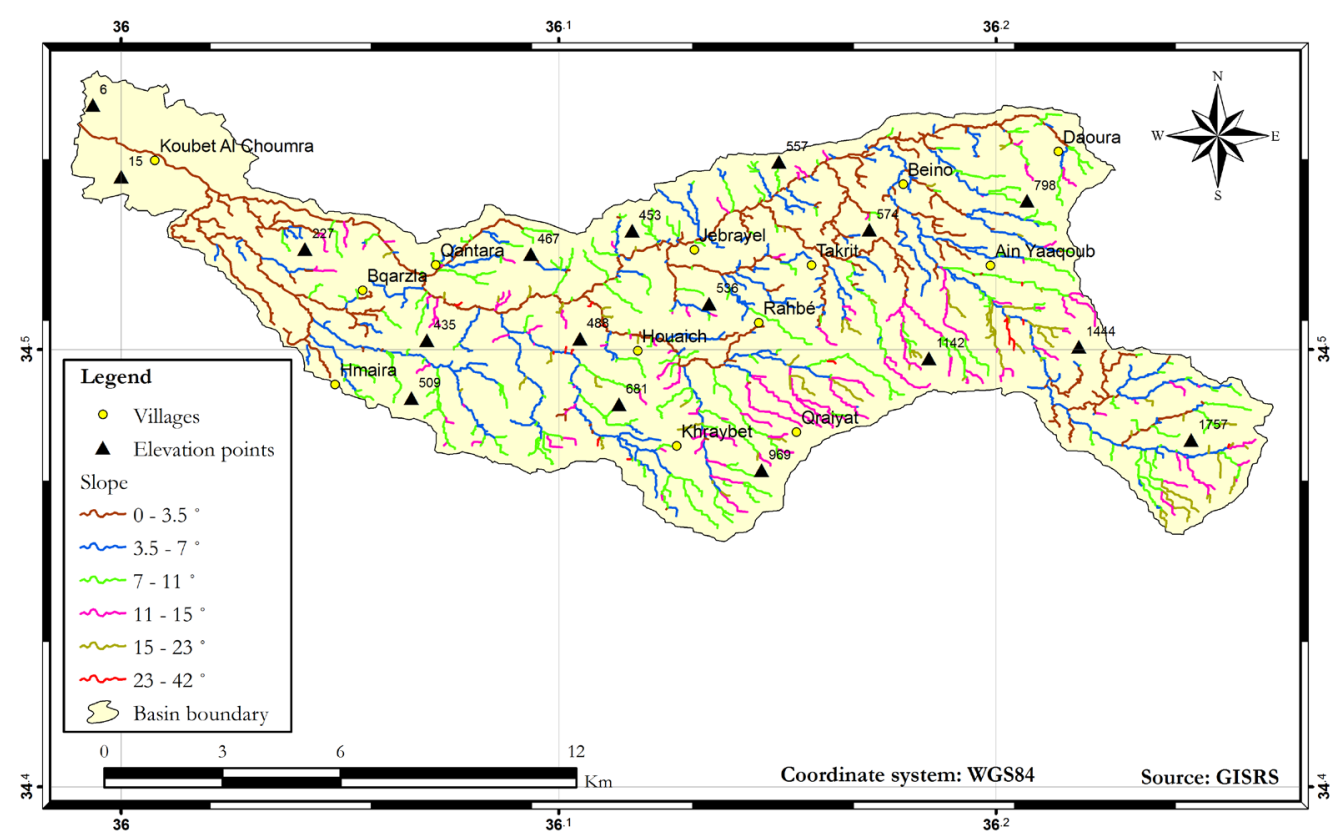

Figure 6. Slopes of streams in ARB.

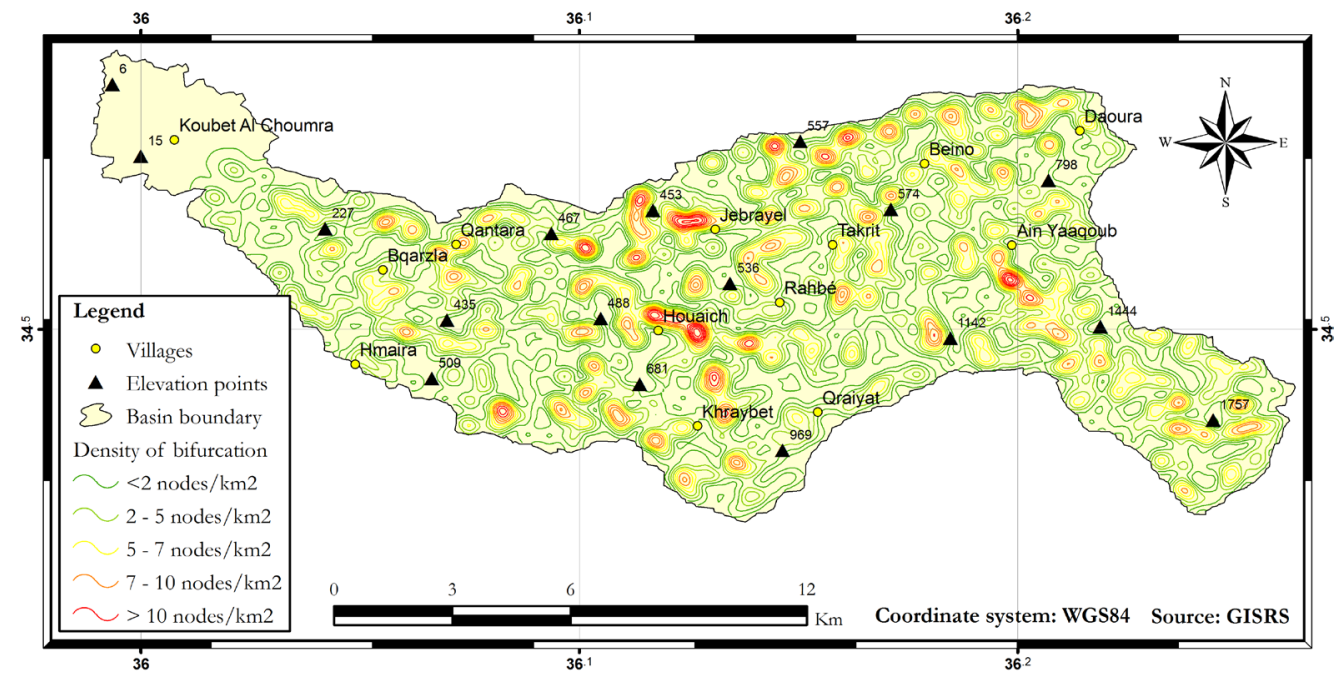

Figure 7. Density of joining streams in ARB.

Table 5. Streams order and slope in ARB.

\begin{tabular}{ccccccc}
\hline \multicolumn{5}{c}{ Stream slope interval } \\
\hline Stream order & $<3.5^{\circ}$ & $3.5^{\circ}-7^{\circ}$ & $7^{\circ}-11^{\circ}$ & $11^{\circ}-15^{\circ}$ & $15^{\circ}-23^{\circ}$ & $23^{\circ}-42^{\circ}$ \\
1 & 107 & 117 & 176 & 103 & 65 & 15 \\
2 & 26 & 42 & 33 & 13 & 5 & 1 \\
3 & 14 & 7 & 2 & 2 & 0 & 0 \\
4 & 5 & 2 & 0 & 0 & 0 & 0 \\
5 & 1 & 0 & 0 & 0 & 0 & 0 \\
Total & 153 & 168 & 211 & 108 & 70 & 16 \\
\hline
\end{tabular}


plied (i.e. L/W, A/P, E, F and K) in this study. This directly influences the hydrography of the running water in streams and in the river discharge at the outlet. It indicates that the peak flow of the Aqra River is low, which is conversely to the fan-shape basins [14]. The basin can be also considered as a small-scale water catchment, with short primary watercourse (i.e. the main river) if compared with the dominant watershed dimensions.

The elongation of ARB with almost gentle sloping terrain makes it vulnerable to fast water accumulation on some localities terrain surface, and thus flood can be an anticipated natural risk, with considerable damage since there are a number of human settlements geographically distributed among the basin boundary, and many of them are located among/or in the proximity of watercourses.

The obtained results for ARB are preliminary numeric values that can be much more analysed and exaggerated, especially once any site or locality are selected for the application of water projects. Therefore, the geometric and morphometric characterization of ARB can be considered as a first hand-information for further geometric and morphometric analysis and in the selection of the proper applications, since it is not possible to apply hydrological controls and applications (such as water harvesting and water storage and supply approaches) without having a detailed diagnoses for the streams behaviour and their interrelation. This is, of course, added to the boundary analysis of the entire basin.

The investigated measures are also helpful to calculate the water budget among the basin, and it can be demonstrated for all watershed and drainage systems in Lebanon which are almost lacking to such morphometric and geometric analysis. It also contributes to a part of the diagnoses of the water cycle in the region.

From the applied study on ARB, it is clear that the use of geomatic techniques is a very helpful tool, and it can give valuable measures which cannot be applicable by conventional tools of analysis. In addition, it serves in reducing time of analysis with least cost, as well as it can cover rugged and remote areas. Therefore, it is recommended to utilize such advanced systematic techniques in order to create a hydrologic database for all of the Lebanese basins at different scales and dimensions.

\section{References}

[1] Shaban, A. (2003) Etude de l’hydroélogie au Liban Occidental: Utilisation de la télédétection. Ph.D. Dissertation, Bordeaux 1 Université, 202 p.

[2] UN (United Nations) (1967) Hydrogeological Map of Lebanon, Carte hydrogéologique du Liban au 1:100000 ème, Beyrouth, Liban.

[3] Shaban, A. and Kayrouz-Khalf, L. (2013) The Geological Controls of the Geothermal Groundwater Sources in Lebanon. International Journal of Energy and Environment (IJEE), 4, 787-796.

[4] El Hage, M. (2012) Etude de la qualité géomorphologique de modèles numériques de terrain issus de l'imagerie spatiale. Ph.D. Thesis, Conservatoire National des Arts et Métiers, Paris, 146 p.

[5] Polidori, L., Claden, M., Frelat, R., El Hage, M., Bendraoua, F., Doliscar, G., Mondesir, P., Piard, B.E. and Gaucherel, C. (2014) ELABORATION DU RÉFÉRENTIEL HYDROGRAPHIQUE D’HAÏTI A PARTIR D’UN MNT ASTER, Revue française de photogrammétrie et de télédétection, (205), 49-57.

[6] Tachikawa, T., Hato, M., Kaku, M. and Iwasaki, A. (2011) Characteristics of ASTER GDEM Version 2. International Geoscience and Remote Sensing Symposium (IGARSS), IEEE, Vancouver, 24-29 July 2011, 3657-3660. http://dx.doi.org/10.1109/igarss.2011.6050017

[7] Hosseinzadeh, S.R. (2011) Assessing the Quality of ASTER DEMs for Hydrological Applications. International Conference on Environment Science and Engineering, 8, 37-41.

[8] Soille, P. (2004) Optimal Removal of Spurious Pits in Grid Digital Elevation Model. Water Resources Research, 40, W1250. http://dx.doi.org/10.1029/2004wr003060

[9] Charleux-Demargne, J. (2004) Qualité des Modèles Numériques de Terrain pour l'Hydrologie. Application à la Caractérisation du Régime de Crues des Bassins Versants. Ph.D. Thesis, University of Montpellier, France, 350 p.

[10] Sanlaville, P. (1977) Etude géomorphologique de la région littorale du Liban, Publications de l’Université Libanaise, section des études géographiques, Beyrouth, tome I.

[11] Schumm, S. (1956) The Elevation of Drainage Systems and Slopes in Bad Lands at Perth Amboy, New Jersey. Geological Society of America Bulletin, 67, 597-646.

http://dx.doi.org/10.1130/0016-7606(1956)67[597:EODSAS]2.0.CO;2

[12] Horton, R. (1932) Drainage-Basin Characteristics. Transactions, American Geophysical Union, 13, 350-361.

[13] Gravelius, H. (1914) Rivers. G.J. göschen Publishing, Berlin, 179 p. 
[14] Musy, A. and Higy, C. (2011) Hydrology: A Science of Nature. Science Pub. Taylor \& Francis Group., New York, $346 \mathrm{p}$.

[15] Pike, R. and Wilson, S. (1971) Elevation-Relief Ratio, Hypsometric Integral and Geomorphic Area-Altitude Analysis. GSA Bulletin, 82, 1079-1084. http://dx.doi.org/10.1130/0016-7606(1971)82[1079:ERHIAG]2.0.CO;2

[16] Strahler, A.N. (1952) Hypsometric (Area Altitude) Analysis of Erosional Topology. Geological Society of America Bulletin, 1117-1142. http://dx.doi.org/10.1130/0016-7606(1952)63[1117:HAAOET]2.0.CO;2 